\title{
Survival analysis and predictors of mortality for adult HIV/AIDS patients following antiretroviral therapy in Mizan-Tepi University Teaching Hospital, Southwest Ethiopia: a retrospective cohort study
}

\author{
Belete Mulatu Teshale ${ }^{1}$, Sisay Awoke ${ }^{2}$ \\ ${ }^{1}$ Mizan-Tepi University, Ethiopia \\ ${ }^{2}$ Addis Ababa University, Ethiopia
}

\begin{abstract}
Introduction: Acquired immune deficiency syndrome (AIDS) is a medical condition caused by human immunodeficiency virus (HIV), and has been the major concern worldwide. Despite antiretroviral treatment (ART) has shown significant clinical importance by meeting the goal of therapy, there is still a number of deaths due to socio-economic, demographic, and health-related factors. Therefore, this study was aimed to investigate the survival status and predictors of mortality for adult HIV-positive patients treated with ART.

Material and methods: A retrospective cohort study was conducted with 1,285 of HIV-infected patients aged 15 years and greater, who were enrolled in ART at Mizan-Tepi University Teaching Hospital from September, 2007 to January, 2015. A multivariable Cox regression model was applied to assess significant predictors of mortality.

Results: During follow-up period, a total of 1,285 patients contributed to 59,237 person-year of followup, and $273(21 \%)$ of the patients died, showing overall incidence rate of 4.6 per 1,000 person-year $(273 / 59,237)$. The median follow-up period was 44 months. During follow-up, 273 (21\%) patients died, of whom nearly $32 \%$ and $12 \%$ of deaths occurred within 6 months and between 6 and 12 months of highly active antiretroviral therapy (HAART) initiation, respectively.

Conclusions: Multivariable Cox proportional hazards model revealed that having concomitant tuberculosis infection, low baseline CD4 count, low baseline weight, living in rural area, using of a substance, older age, lower educational level, higher World Health Organization (WHO) clinical stages, functional status, and marital status were all significantly associated with progression to death for HIV/AIDS-infected patients.
\end{abstract}

HIV AIDS Rev 2022; 21, 1: 58-68 DOI: https://doi.org/10.5114/hivar.2022.112758

Key words: Ethiopia, HIV/AIDS, retrospective study, predictors of death.

Address for correspondence: Belete Mulatu Teshale, Mizan-Tepi University, Ethiopia, e-mail: alimulatu@gmail.com
Article history:

Received: 22.06.2020

Received in revised form: 05.03.2021

Accepted: 07.05.2021

Available online: 18.01.2022
International Journal

of HIV-Related Problems

HIV \& AIDS

R e v i e w 


\section{Introduction}

Acquired immune deficiency syndrome (AIDS) is a medical condition caused by human immunodeficiency virus (HIV), and is the major concern worldwide. The discovery of HIV as the causative body of AIDS, and the inability of modern medicine to find a cure for the disease, have placed HIV as one of the most dreaded pathogens of the $21^{\text {st }}$ century. Expansion of the epidemic has now become a burning issue globally, and this is even more in developing countries, especially in sub-Saharan Africa. Today, it is one of the largest public health crises endangering the human race. In almost three decades since first HIV cases were recognized, it has claimed the lives of millions of people making, it one of the most devastating epidemics. The disease, being without any cure, is still responsible for economic, social, and health crises in many developing countries [1].

Currently, there was no cure for HIV infection, and viable vaccine candidates were years away. Yet, the development of life-saving antiretroviral drugs had brought new hope. In high-income countries, combination of antiretroviral therapy had extended and improved life's of people living with HIV/AIDS, and transformed perceptions of HIV/ AIDS from a fatal disease to a manageable, chronic illness. In poorer parts of the world, in which HIV/AIDS had spread most rapidly, this transformation has not yet happened. In addition, several observational studies, mostly done in resource-rich settings, documented that HIV-infected patients receiving ART had higher rates of survival compared with patients who were not on ART. Currently, the widespread use of highly active antiretroviral therapy (HAART) in developing countries has reduced the risk of treated HIV-infected individuals by $70-90 \%$, compared with untreated cases [2].

Globally, the number of people living with HIV receiving treatment in resource-poor countries has dramatically increased in the past decades. At the end of 2019, an estimated 38 million people globally were living with HIV/AIDS, of whom around 25.4 million people living with HIV (67\% of the total) were accessing antiretroviral therapy. However, an estimated 12.6 million of other people living with HIV (33\% of the total) were still not accessing ART. Since the start of HIV/AIDS epidemic (end of 2019), globally, about 75.5 million people had been infected with HIV, and 32.7 million people have died from AIDS-related illnesses. Worldwide, an estimated 1.7 million people became newly infected with HIV, and nearly 0.7 million people have died from AIDS-related illnesses in 2019 [3, 4].

Ethiopia is a large, predominantly rural country, and the second most populous country in Africa (after Nigeria), with a total population of about 79 million, growing at an annual rate of 2.6\%, according to the 2007 National Census [5]. At the end of 2016, there were an estimated 710,000 of people living with HIV, of whom 648,000 were adults [6].

In Ethiopia, HAART began in 2003, and free ART was launched in 2005. Recently, ART services are made available in more than 1,361 health facilities, of which around 909 are health centers. Based on the new spectrum estimate for 2017,
ART coverage for adults (age $>15$ ) has reached the rate of $75 \%$, but the coverage remains low (34\%) for children (age $<15$ ) living with HIV $[1,6]$. More than 473,000 patients were enrolled in HIV/AIDS care, and 268,934 individuals were started on HAART. In 2016, the HIV/AIDS epidemic in Ethiopia was generalized with significant heterogeneity between urban and rural areas, with estimated national prevalence of $0.9 \%$. Urban prevalence was $2.9 \%$, which was 7 -times higher than that of rural (0.4\%) [5].

Clinical benefit of ART for AIDS patients, in terms of mortality reduction and improved quality of life, is wellestablished in developing countries. Moreover, survival rate of HIV/AIDS patients on HAART and risk factors of mortality of these patients have been very well understood. However, in resource poor countries, like Ethiopia, there are higher mortality rates, with poorly understood contributing factors. In other words, even if ART treatment has shown significant clinical importance by meeting the goal of therapy, there are still deaths, which can be avoided by appropriate interventions with certain socio-economic, demographic, behavioral risk, and health factors. Therefore, a better knowledge of prognostic factors would allow for closer follow-up and more targeted interventions in high-risk patients, leading to reducing excess mortality [7]. For this reason, the present study investigated the survival status and predictors of mortality for adult HIV-positive patients on ART in Mizan-Tepi University Teaching Hospital, Southwest Ethiopia.

\section{Material and methods}

\section{Study design, area, and period}

A retrospective cohort study was conducted among adult HIV-positive patients on ART between September 2007 to January 2015, and followed-up until July 30, 2015. The study was conducted at Mizan-Tepi University Teaching Hospital, $570 \mathrm{~km}$ far away from Addis Ababa, capital and the largest city of Ethiopia. ART service was successfully established in 2003 in the hospital. It has a separate ART clinic and units for ART follow-up of people living with HIV (PLHIV), with nurses, pharmacy, data clerks, patients' adherence rooms, equipment, etc. In addition to adherence counseling and supplying ART for HIV patients, the clinic also provides screening, follow-up, and referral services of tuberculosis (TB) patients.

\section{Data collection and quality control}

Data were collected by two experienced ART nurses trained on comprehensive HIV care and working in ART clinic in the hospital. A supervisor supervised the data collection process. Data collectors and the supervisor were trained on data collection procedures for two days. The investigator supervised the overall process. All completed data collection forms were investigated for completeness, consistency, and clarity during data management, storage, and analysis. This study reviewed patients' intake forms and 
follow-up cards of adult HIV/AIDS patients by identifying socio-demographic characteristics, and baseline clinical and laboratory variables. Most recent laboratory results before starting ART were used as a baseline value. If there were no pre-treatment laboratory evaluates, results obtained within one month of ART initiation were employed as baseline.

\section{Exclusion and inclusion criteria}

Patients who initiated treatment outside MTU Teaching Hospital, pregnant women, lactating mothers on PMTCT, and patients with competing causes of death (accident, or any non-AIDS malignancies) were excluded. We analyzed clinical and demographic characteristics at the time of initiation of ART therapy as potential predictors of mortality.

\section{Sample size determination and sampling techniques}

Sample size plays a pivotal role in overall design of a research. In this study, an appropriate sample size was the minimum number of patients under ART. There was a number of issues/points that had to be considered to determine the optimal sample size. Some of the issues included objective of the research, target population, design of the research, degree of precision required for generalization, key estimates desired, allowance for non-response, and available budget.

The sample size was determined using single-population proportion formula, with $p=18 \%$ as prevalence (proportion) of deaths among HIV/AIDS adults on ART, according to a previous study conducted at Jimma University Specialized Hospital [8], with $d=2.1 \%$ of marginal error and $95 \%$ confidence interval (CI) of certainty $(\alpha=0.05)$. Accordingly, the sample size determination formula (Cochran, 1977) was as follow:

$$
n=\left(\frac{\left(Z_{\alpha 12}\right)^{2} \times P \times(1-P)}{d^{2}}\right)=\left(\frac{(1.96)^{2} \times 0.18 \times 0.82}{0.021^{2}}\right)=1,285 \text { patients }
$$

Therefore, the sample size using the given formula was $n=1,285$ patients for the current study. Patients were selected using systematic random sampling based on their unique ART number, which is assigned to a patient treated with ART.

\section{Study variables and endpoints of the study}

Response/outcome variable was survival time of HIV/ AIDS patients measured in months, which was the time from ART start date until date of death/exclusion. In this study, the event was death of a patient. Independent (predictor) variables included in the model were socio-demographic characteristics (age, sex, place of residence, marital status, employment, educational status, and number of dependent children), baseline clinical laboratory and ART information (past opportunistic illness, World Health Organization [WHO] clinical staging, TB test and treatment, weight, functional status,
ARV drug regimen type, substance use, drug allergies, CD4 count, disclosure status, and side effects), and ART treatment.

\section{Lost to follow-up, transfers, and deaths}

Adults were considered lost to follow-up if they did not collect treatment for 3 consecutive months. Attempts were made to contact all adults who were lost to follow-up to determine their status. All lost to follow-ups and transfers were excluded from the study on the date of their last visit. Otherwise, follow-up time was censored at the end of the study period. Death events were defined as all-cause deaths occurring after ART initiation before July 30, 2015 at the end of study period. Deaths were confirmed by hospital records or family interviews. Survival time was calculated in months as the time between date of treatment initiation and date of event (death) or date of exclusion. Finally, alive individuals on HAART were censored on July 30, 2015 at end of study period.

\section{Statistical analysis}

Data analysis was conducted by STATA version 11.0 (Stata Corp.; USA). Descriptive survival analysis was performed using Kaplan-Meier assessment to compare survival time in different groups. Hazard ratio and predictors of mortality of HAART patients over a period of time $t$ were analyzed using Cox proportional hazards model. The association of every independent variable was evaluated with dependent variable and baseline variables significant at $p$-value of $<0.2$, with bivariate analysis included in multivariable Cox regression model. Furthermore, to identify potential predictors of mortality for HIV/AIDS-infected patients, forward selection method was applied. Eventually, only those variables, which remained significant at $p \leq 0.05$ in final model were considered independent predictors of death for HIV/ AIDS-infected patients. $P$-value of $\leq 0.05$ and confidence level of $95 \%$ were considered statistically significant.

\section{Results}

\section{Baseline clinical and laboratory characteristic of the study participants}

A total of 1,285 patients' records enrolled on ART were included in this study. Of the total, nearly $46 \%$ of the participants had CD4 cell count of less than 200 cells $/ \mathrm{mm}^{3}$ at a time of treatment initiation, and majority (49\%) of the patients were under the age group of 15-30 years. Furthermore, at the time of ART initiation, 455 (58\%) of the patients presented WHO clinical stage III and IV, and 610 (47.5\%) of them were receiving TDF-3TC-EFV ART regimen. Among the study participants, 296 (23\%) had developed active TB infection, and $40.6 \%$ (522) of the patients experienced opportunistic illnesses. With regard to chemoprophylaxis, majority 937 (73\%) of the patients have received cotrimoxazole, and 540 (42\%) were under isoniazid (INH) preventive therapies (Table 1). 
Table 1. Baseline clinical and laboratory characteristic of the study participants

\begin{tabular}{|c|c|c|c|c|c|c|}
\hline \multirow[t]{3}{*}{ Factor } & \multicolumn{6}{|c|}{ Survival status } \\
\hline & \multicolumn{2}{|c|}{ Dead } & \multicolumn{2}{|c|}{ Censored } & \multicolumn{2}{|c|}{ Total } \\
\hline & $n$ & $\%$ & $n$ & $\%$ & $n$ & $\%$ \\
\hline \multicolumn{7}{|l|}{ CD4 count $/ \mathrm{mm}^{3}$} \\
\hline$<200$ & 173 & 63.4 & 415 & 41.0 & 588 & 46.0 \\
\hline $200-350$ & 91 & 33.3 & 331 & 32.7 & 422 & 33.0 \\
\hline$>350$ & 9 & 3.3 & 266 & 26.3 & 275 & 21.0 \\
\hline \multicolumn{7}{|c|}{ Past opportunistic illness } \\
\hline Yes & 178 & 65.2 & 344 & 34.0 & 522 & 40.6 \\
\hline No & 95 & 34.8 & 668 & 66.0 & 763 & 59.4 \\
\hline \multicolumn{7}{|l|}{ TB test result } \\
\hline Positive & 134 & 49.0 & 229 & 23.0 & 363 & 28.0 \\
\hline Negative & 139 & 51.0 & 783 & 77.0 & 922 & 72.0 \\
\hline \multicolumn{7}{|l|}{ Age group } \\
\hline $15-30$ & 111 & 41.0 & 523 & 52.0 & 634 & 49.0 \\
\hline $30-45$ & 126 & 46.0 & 425 & 42.0 & 551 & 43.0 \\
\hline $45-100$ & 36 & 13.0 & 64 & 6.0 & 100 & 8.0 \\
\hline \multicolumn{7}{|l|}{ Medication } \\
\hline INH & 28 & 10.3 & 512 & 50.6 & 540 & 42.0 \\
\hline Cotrimoxazole & 169 & 61.9 & 768 & 75.9 & 937 & 72.9 \\
\hline Fluconazole & 43 & 15.8 & 89 & 8.8 & 132 & 10.3 \\
\hline \multicolumn{7}{|l|}{ ARV drug regimen } \\
\hline TDF-3TC-NVP & 20 & 7.3 & 63 & 6.2 & 83 & 6.5 \\
\hline TDF-3TC-EFV & 103 & 37.7 & 507 & 50.1 & 610 & 47.5 \\
\hline AZT-3TC-NVP & 60 & 22.0 & 234 & 23.1 & 294 & 22.9 \\
\hline AZT-3TC-EFV & 7 & 2.6 & 53 & 5.2 & 60 & 4.7 \\
\hline D4T-3TC-NVP & 54 & 19.8 & 87 & 8.6 & 141 & 11.0 \\
\hline D4T-3TC-EFV & 29 & 10.6 & 68 & 6.7 & 97 & 7.5 \\
\hline \multicolumn{7}{|l|}{ WHO stage } \\
\hline 1 & 45 & 16.5 & 260 & 25.7 & 305 & 23.7 \\
\hline II & 42 & 15.4 & 243 & 24.0 & 285 & 22.2 \\
\hline III & 89 & 32.6 & 401 & 39.6 & 490 & 38.1 \\
\hline IV & 97 & 35.5 & 108 & 10.7 & 205 & 16.0 \\
\hline \multicolumn{7}{|l|}{ Functional status } \\
\hline Working & 107 & 39.2 & 56 & 64.8 & 763 & 59.4 \\
\hline Ambulatory & 90 & 33.0 & 296 & 29.2 & 386 & 30.0 \\
\hline Bedridden & 76 & 27.8 & 60 & 5.9 & 136 & 10.6 \\
\hline Total & 273 & 21.0 & 1,012 & 79 & 1,285 & 100 \\
\hline
\end{tabular}

\section{Baseline demographic characteristics of the study participants}

Among 1,285 patients, 273 (21.2\%) died during followup, and the remaining 1,012 (78.8\%) individuals were alive and censored at the end of the study. Of the study participants, $820(63.8 \%)$ were urban residents, 906 (70.5\%) had less than a high school education, and 617 (48\%) of the patients were married at a time of treatment initiation. Majority were women $750(58.4 \%)$, and $689(53.6 \%)$ of the patients were followers of Orthodox religion. Furthermore, among all the patients, 310 (24.1\%) were not working due to illness or unemployment, and $722(56.2 \%)$ of the participants had dependent children at home (Table 2). 
Table 2. Baseline socio-demographic characteristics of the study participants

\begin{tabular}{|c|c|c|c|c|c|c|}
\hline \multirow[t]{3}{*}{ Factor } & \multicolumn{6}{|c|}{ Survival status } \\
\hline & \multicolumn{2}{|c|}{ Dead } & \multicolumn{2}{|c|}{ Censored } & \multicolumn{2}{|c|}{ Total } \\
\hline & $n$ & $\%$ & $n$ & $\%$ & $n$ & $\%$ \\
\hline \multicolumn{7}{|l|}{ Gender } \\
\hline Male & 101 & 37.0 & 434 & 42.9 & 535 & 41.6 \\
\hline Female & 172 & 63.0 & 578 & 57.1 & 750 & 58.4 \\
\hline \multicolumn{7}{|l|}{ Marital status } \\
\hline Never married & 144 & 52.7 & 206 & 20.4 & 350 & 27.2 \\
\hline Married & 83 & 30.4 & 534 & 52.8 & 617 & 48.0 \\
\hline Separated & 31 & 11.4 & 134 & 13.2 & 165 & 12.8 \\
\hline Divorced & 10 & 3.7 & 97 & 9.6 & 107 & 8.3 \\
\hline Widow & 5 & 1.8 & 41 & 4.1 & 46 & 3.6 \\
\hline \multicolumn{7}{|l|}{ Education level } \\
\hline No formal education & 82 & 30.0 & 247 & 24.4 & 329 & 25.6 \\
\hline Primary & 117 & 42.9 & 460 & 45.5 & 577 & 44.9 \\
\hline Secondary & 56 & 20.5 & 228 & 22.5 & 284 & 22.1 \\
\hline Tertiary & 18 & 6.6 & 77 & 7.6 & 95 & 7.4 \\
\hline \multicolumn{7}{|l|}{ Religion } \\
\hline Muslim & 58 & 21.2 & 264 & 26.1 & 322 & 25.1 \\
\hline Orthodox & 140 & 51.3 & 549 & 54.2 & 689 & 53.6 \\
\hline Protestant and others & 75 & 27.5 & 199 & 19.7 & 274 & 21.3 \\
\hline \multicolumn{7}{|l|}{ Have children } \\
\hline Yes & 93 & 34.1 & 629 & 62.2 & 722 & 56.2 \\
\hline No & 180 & 65.9 & 383 & 37.8 & 563 & 43.8 \\
\hline \multicolumn{7}{|l|}{ Place of residence } \\
\hline Rural & 143 & 52.4 & 322 & 31.8 & 465 & 36.2 \\
\hline Urban & 130 & 47.6 & 690 & 68.2 & 820 & 63.8 \\
\hline \multicolumn{7}{|l|}{ Current employment status } \\
\hline Working full time & 88 & 32.2 & 707 & 69.9 & 795 & 61.9 \\
\hline Working part-time & 58 & 21.2 & 122 & 12.1 & 180 & 14.0 \\
\hline $\begin{array}{l}\text { Not working/ studying } \\
\text { due to ill health }\end{array}$ & 92 & 33.7 & 101 & 10.0 & 193 & 15.0 \\
\hline Unemployed & 35 & 12.8 & 82 & 8.1 & 117 & 9.1 \\
\hline Total & 273 & 21.0 & 1,012 & 79 & 1,285 & 100.0 \\
\hline
\end{tabular}

\section{Summary statistics of continuous variables considered in the study}

At the time of ART initiation, the overall mean weight, CD4 count, and age of the patients were $50 \mathrm{~kg}, 237.6$ cells/ $\mathrm{mm}^{3}$, and 33 years, respectively. Furthermore, for the 273 dead patients, the mean weight, CD4 count, and age of were $44 \mathrm{~kg}, 163$ cells $/ \mathrm{mm}^{3}$, and 35 years, respectively (Table 3).

\section{Descriptive survival analysis (follow-up)}

During the follow-up period, a total of 1,285 patients contributed to 59,237 person-years follow-up, and 273 (21\%) of the patients died, showing an incidence rate of 4.6 per 1,000 person-years $(273 / 59,237)$. The overall mean estimated survival time of the participants was 46 months, while the average treatment time for the dead patients was 26 months. Of a total of 273 (21\%) of the dead patients, $31.9 \%(87 / 273)$ died within 6 months of ART treatment initiation, $11.72 \%$ $(32 / 273)$ died between $6^{\text {th }}$ and $12^{\text {th }}$ month of ART treatment initiation, and 44\% (119/273) died within 12 months of ART treatment initiation. The overall probability of surviving up to 102 months was $63.54 \%$, with the probability of survival for 12, 24, and 36 months after starting ART treatment with $87.1 \%, 83.51 \%$, and $80.24 \%$, respectively (Table 4 ). 
Table 3. Summary statistics of continuous variables considered in this study

\begin{tabular}{|c|c|c|c|c|}
\hline Survival status & Survival time (months) & CD4 count $/ \mathrm{mm}^{3}$ & Age (years) & Weight (kg) \\
\hline \multicolumn{5}{|l|}{ Dead/event } \\
\hline Mean & 26.37 & 162.96 & 35.03 & 44.17 \\
\hline Median & 19.67 & 154.00 & 35.00 & 44.00 \\
\hline Minimum & 0.07 & 28.00 & 17.00 & 29.00 \\
\hline Maximum & 99.47 & 931.00 & 67.00 & 63.00 \\
\hline Range & 99.40 & 903.00 & 50.00 & 34.00 \\
\hline Standard deviation & 25.57 & 102.57 & 9.84 & 6.43 \\
\hline \multicolumn{5}{|l|}{ Censored } \\
\hline Mean & 51.42 & 257.68 & 32.19 & 51.66 \\
\hline Median & 53.28 & 238.00 & 30.00 & 51.00 \\
\hline Minimum & 1.73 & 27.00 & 15.00 & 23.00 \\
\hline Maximum & 101.43 & $1,006.00$ & 80.00 & 91.00 \\
\hline Range & 99.70 & 979.00 & 65.00 & 68.00 \\
\hline Standard deviation & 28.85 & 151.42 & 8.62 & 9.36 \\
\hline \multicolumn{5}{|l|}{ Overall } \\
\hline Mean & 46.10 & 237.56 & 32.79 & 50.07 \\
\hline Median & 44.30 & 214.00 & 31.00 & 50.00 \\
\hline Minimum & 0.07 & 27.00 & 15.00 & 23.00 \\
\hline Maximum & 101.43 & $1,006.00$ & 80.00 & 91.00 \\
\hline Range & 101.37 & 979.00 & 65.00 & 68.00 \\
\hline Standard deviation & 29.98 & 147.59 & 8.97 & 9.33 \\
\hline
\end{tabular}

Table 4. Actuarial life table estimates of the cumulative progression to death for the 1,285 study subjects starting ART between 2007 and 2015 at the MTU Teaching Hospital

\begin{tabular}{c|c|c|c|c|c|c}
\hline $\begin{array}{c}\text { Interval start time } \\
\text { in months (months } \\
\text { of follow-up) }\end{array}$ & $\begin{array}{c}\text { Number } \\
\text { of entering } \\
\text { interval }\end{array}$ & $\begin{array}{c}\text { Number } \\
\text { of withdrawing } \\
\text { during interval }\end{array}$ & $\begin{array}{c}\text { Number } \\
\text { of deaths }\end{array}$ & $\begin{array}{c}\text { Proportion } \\
\text { of deaths }\end{array}$ & $\begin{array}{c}\text { Proportion } \\
\text { of surviving }\end{array}$ & $\begin{array}{c}\text { Cumulative proportion } \\
\text { of surviving } \\
\text { at the end of interval }\end{array}$ \\
\hline 0 & 1,285 & 3 & 56 & 0.0436 & 0.9564 & 0.9564 \\
\hline 3 & 1,226 & 25 & 31 & 0.0255 & 0.9745 & 0.9319 \\
\hline 6 & 1,170 & 25 & 18 & 0.0156 & 0.9844 & 0.9174 \\
\hline 9 & 1,127 & 44 & 14 & 0.0127 & 0.9873 & 0.9058 \\
\hline 12 & 1,069 & 153 & 36 & 0.0363 & 0.9637 & 0.8710 \\
\hline 24 & 880 & 107 & 34 & 0.0411 & 0.9589 & 0.8351 \\
\hline 36 & 739 & 101 & 27 & 0.0392 & 0.9608 & 0.8024 \\
\hline 48 & 611 & 113 & 16 & 0.0289 & 0.9711 & 0.7792 \\
\hline 60 & 482 & 122 & 23 & 0.0546 & 0.9454 & 0.7367 \\
\hline 72 & 337 & 165 & 9 & 0.0354 & 0.9646 & 0.7106 \\
\hline 96 & 163 & 102 & 8 & 0.0714 & 0.9286 & 0.6599 \\
\hline
\end{tabular}

The graph of the estimate of overall Kaplan-Meier survivor function showed that most of deaths occurred in earlier months of ART treatment initiation, which declined in later months of follow-up time (Figure 1).
Moreover, Kaplan-Meir survival figures revealed that patients with no past TB history, those who were not using substances, had CD4 count greater than $350 \mathrm{cell} / \mathrm{mm}^{3}$, being working functional status urban dwellers, with WHO clinical 


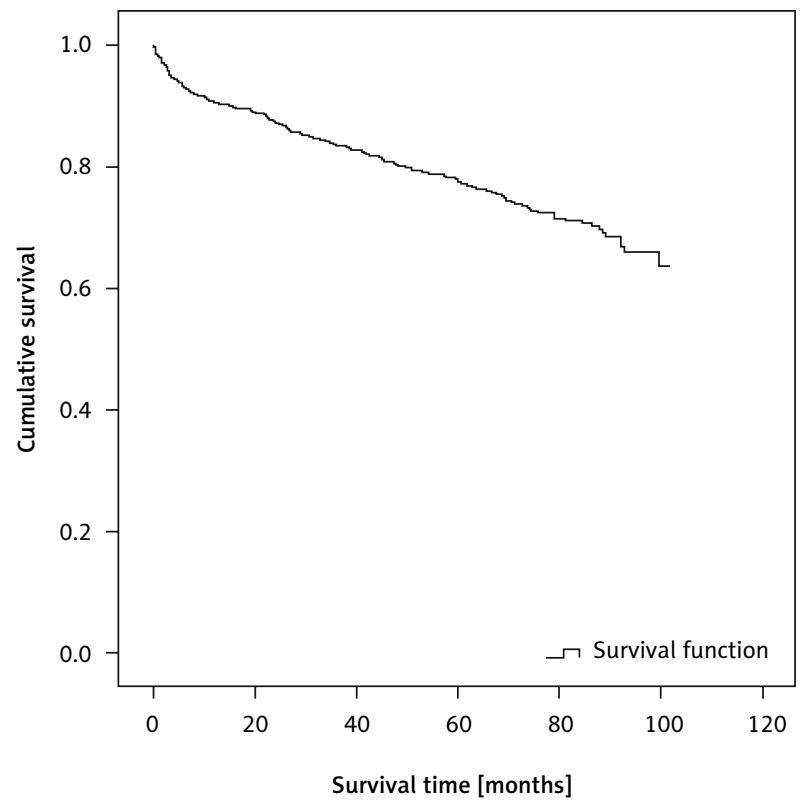

Figure 1. The plot of the overall estimate of Kaplan-Meier survivor function of HIV/AIDS infected patients treated under ART between 2007 and 2015 in MTU Teaching Hospital

stage I, and with no past history of opportunistic illness, had better survival outcomes as compared to their counterparts (Figure 2).

\section{Predictors of mortality for HIV/AIDS- infected patients}

In univariable Cox regression model, advanced WHO clinical stages, past TB history, low baseline bodyweight, past opportunistic illness, low baseline CD4 count, living in rural place, substance usage, older age, low level of education, functional status, marital status, and ARV regimen type, were all significantly associated with progression to death.

In multivariable Cox regression analysis, significant predictors of mortality included past TB history (adjusted hazard ratio $[\mathrm{AHR}]=1.790 ; 95 \% \mathrm{CI}: 1.387-2.310$ ), low baseline CD4 count $(\mathrm{AHR}=5.45$; 95\% CI: 2.77-10.73), low baseline weight $(A H R=0.934 ; 95 \%$ CI: 0.918-0.950), living in rural area $(\mathrm{AHR}=1.519 ; 95 \% \mathrm{CI}: 1.179-1.957)$, substance usage $(\mathrm{AHR}=1.792 ; 95 \% \mathrm{CI}: 1.40-2.29)$, older age $(\mathrm{AHR}=2.102$; 95\% CI: 1.413-3.125), low education level $(\mathrm{AHR}=2.071 ; 95 \%$ CI: 1.10-3.90), advanced WHO clinical stage $(\mathrm{AHR}=1.60$ $95 \%$ CI: 1.02-2.53), bedridden functional status $(\mathrm{AHR}=2.54$; 95\% CI: 1.86-3.48), and single-marital status $(\mathrm{AHR}=2.70$; 95\% CI: 1.98-3.69) (Table 5).

\section{Discussion}

The present study has shown that patients having concomitant TB infection had almost a 2-fold higher risk of mortality than those who did not present with concom- itant TB infection during follow-up period $(\mathrm{AHR}=1.79$; 95\% CI: 1.39-2.31). Several studies performed across many parts of Africa and Ethiopia have reported that past TB co-infection at baseline was associated with high level of mortality among patients on ART [9-15]. Indeed, a study conducted in Cameroon indicated that patients with past TB co-infection showed 2.35-times more risk of death than those who without TB co-infection [16]. Another study conducted in Tanzania showed TB as a strong predictor of mortality; patients with past TB co-infection had nearly 15-times higher risk of dying as compared to those who did not have TB co-infection. Similar study conducted in Wolisso in central Ethiopia reported past TB co-infection as a predictor of mortality [17]. This might be that delay in diagnosis and treatment as well as no TB prophylaxis contributed to higher mortality. In addition, TB is additionally responsible for the highest risk of mortality and morbidity for HIV/ AIDS-infected patients worldwide.

The other relevant finding of the current study was a highly significant negative association of baseline body weight with mortality (AHR $=0.93$; 95\% CI: 0.92-0.95). Since the estimated hazard ratio was less than unity, other things being equal, the higher the weight of patient, the lower the hazard of death at any given time. For appropriateness of interpretation, for a $5 \mathrm{~kg}$ increase in weight, there was a $29 \%$ lower risk of mortality in patients under ART $[\mathrm{AHR}=0.71=\exp (-0.068 \times 5) ; 95 \% \mathrm{CI}=0.65-0.78=\exp$ $(5 \times(-0.068 \pm 1.96 \times 0.009))]$. A study conducted in Northern Ethiopia by Zinabu et al. reported that for a $5 \mathrm{~kg}$ increase in weight, there was a $12 \%$ lower risk of mortality in patients on ART, which is in line with the current study [11]. In another study conducted in Northern India by Jaya et al., it was found that a weight category of less than $45 \mathrm{~kg}$ was associated with mortality at multivariable level of analysis ( $\mathrm{HR}=4.31,95 \% \mathrm{CI}: 1.70-10.91)$, which is consistent with the current study [18]. In many other studies, body mass index (BMI) was found to be significant predictor of mortality, but in our data set, height was incomplete, thus baseline weight as proxy indicator of nutritional status was used.

In the current study, CD4 count was another significant predictor of death. Patients with CD4 count $<200$ cells per cubic millimeter had a 5 -fold higher risk of mortality as compared to patients who presented greater than or equal to 350 cells per cubic millimeter $(\mathrm{AHR}=5.45 ; 95 \% \mathrm{CI}$ : 2.77-10.73). Once again, the risk of mortality was nearly 4-times higher for those with CD4 cell count between 200 and 350 cells per cubic millimeter, as compared to those with CD4 count greater than or equal to 350 cells per cubic millimeter $(\mathrm{AHR}=3.91 ; 95 \% \mathrm{CI}$ : 1.96-7.82). Majority of previous studies in Ethiopia also found twice or more risk of mortality for patients with lower CD4 count compared to those with a CD4 count of $>350$ cells/ml $[11,15$, 19-23]. Studies performed across many parts of Africa and Asia reported that low level of CD4 count at baseline was associated with high level of mortality among patients on ART [16, 18, 24, 25].

In addition, being rural area dweller was significantly associated with mortality in this study. Patients living in rural 

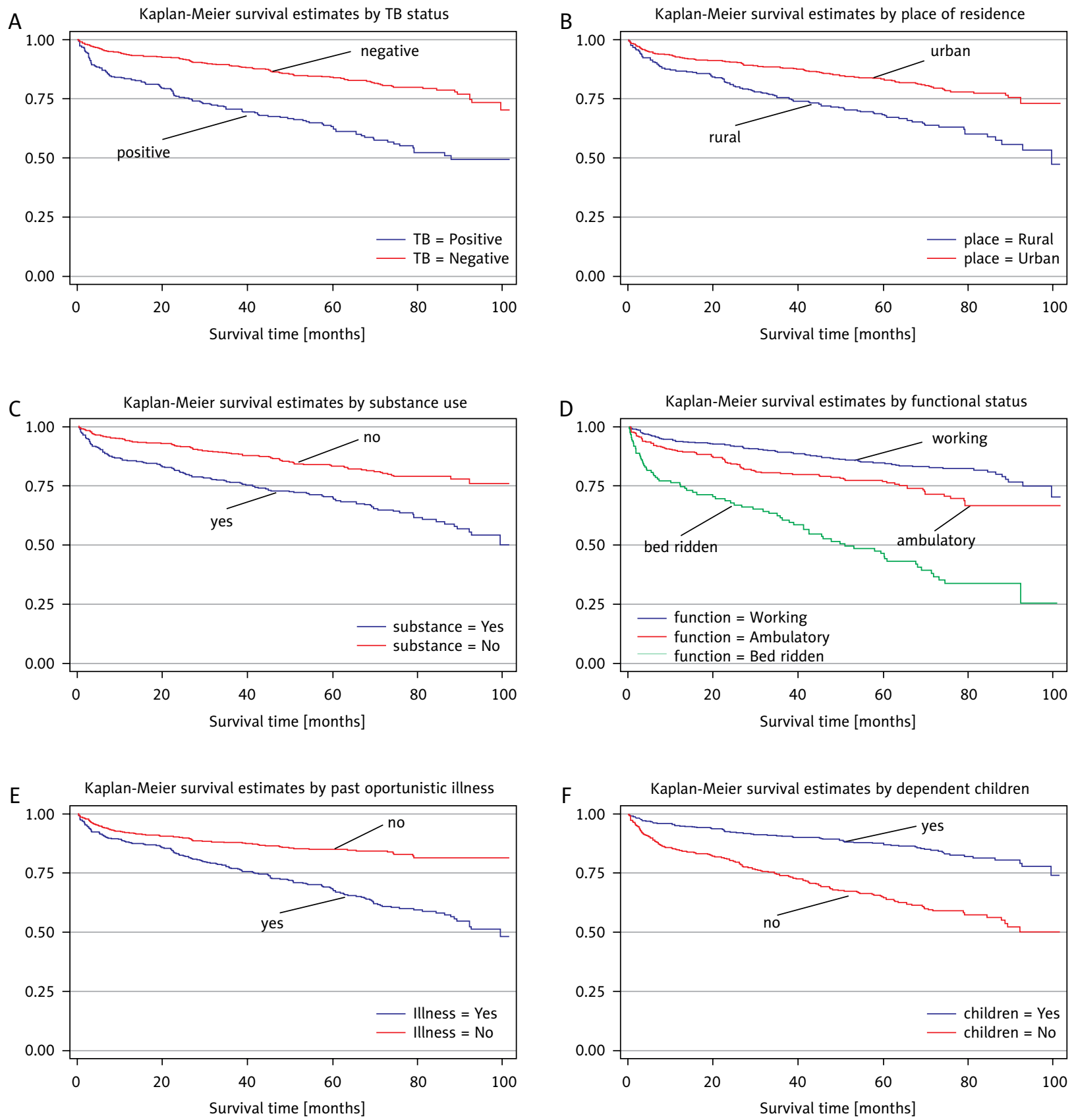

Figure 2. Plots of Kaplan-Meier survivor functions, by A) TB status, B) place of residence, C) substance use, D) functional status, E) opportunistic infection, F) dependent children, for HIV/AIDS infected patients treated under ART between 2007 and 2015 in MTUTH

area were 1.5 -times more likely to die as compared to those living in urban areas (AHR $=1.52$; 95\% CI: 1.18-1.96). This finding is in accordance with results of a previous study conducted in Dessie, northeast Ethiopia [13]. This might be due to lower socio-economic status, reduced awareness about ART, lower food access and diversity, and narrower availability of healthcare in rural dwellers than for people living in urban areas, as these factors are commonly observed in third world and developing countries.
Previous studies reported that patient's age was found to be predictor of mortality, where most of patients in older age were more likely to die $[18,21,24]$. Our study also revealed similar outcome. It was found that the patients who started ART in older age ( $>45$ years) have a 2 -fold higher risk of dying than those who baseline age was within 15 and 30 years $(\mathrm{AHR}=2.10 ; 95 \% \mathrm{CI}: 1.41-3.12)$. Other studies done across many parts of Ethiopia also reported the same result that patients with older age have higher risk of mortality compared to 
Table 5. Crude (unadjusted) and adjusted hazard ratios (HR) of socio demographic, clinical, and laboratory variables

\begin{tabular}{|c|c|c|c|c|}
\hline Factors (covariates) & Crude HR $(95 \% \mathrm{CI})$ & $p$-value & Adjusted HR $(95 \% \mathrm{Cl})$ & $p$-value \\
\hline \multicolumn{5}{|l|}{ TB co-infected } \\
\hline Yes & $2.692(2.123,3.413)$ & $0.000^{*}$ & $1.790(1.387,2.310)$ & $0.000^{*}$ \\
\hline No & 1 & - & 1 & - \\
\hline Baseline weight in $\mathrm{kg}$ & $0.916(0.902,0.930)$ & $0.000^{*}$ & $0.934(0.918,0.950)$ & $0.000^{*}$ \\
\hline \multicolumn{5}{|c|}{ Baseline CD4 count category } \\
\hline$\leq 200$ & $9.067(4.638,17.721)$ & $0.000^{*}$ & $5.451(2.770,10.727)$ & $0.000^{*}$ \\
\hline $200-350$ & $6.414(3.234,12.723)$ & $0.000^{*}$ & $3.914(1.960,7.817)$ & $0.000^{*}$ \\
\hline$>350$ & 1 & - & 1 & - \\
\hline \multicolumn{5}{|l|}{ Place of residence } \\
\hline Urban & 1 & - & 1 & - \\
\hline Rural & $2.063(1.626,2.617)$ & $0.000^{*}$ & $1.519(1.179,1.957)$ & $0.001^{*}$ \\
\hline \multicolumn{5}{|l|}{ Baseline age group in years } \\
\hline $15-30$ & 1 & - & 1 & - \\
\hline $30-45$ & $1.192(0.923,1.539)$ & 0.178 & $1.238(0.949,1.613)$ & 0.115 \\
\hline $45-100$ & $2.050(1.407,2.986)$ & $0.000^{*}$ & $2.102(1.413,3.125)$ & $0.000^{*}$ \\
\hline \multicolumn{5}{|l|}{ Substance users } \\
\hline Yes & $2.154(1.692,2.742)$ & $0.000^{\star}$ & $1.792(1.400,2.295)$ & $0.000^{*}$ \\
\hline No & 1 & - & 1 & - \\
\hline \multicolumn{5}{|l|}{ Education level } \\
\hline No formal education & $2.456(1.320,4.570)$ & $0.005^{*}$ & $2.071(1.01,3.896)$ & $0.024^{*}$ \\
\hline Primary education & $1.660(0.892,3.089)$ & 0.110 & $1.899(1.011,3.570)$ & $0.046^{*}$ \\
\hline Secondary education & $1.435(0.747,2.757)$ & 0.279 & $1.276(0.653,2.493)$ & 0.476 \\
\hline College/above & 1 & - & 1 & - \\
\hline \multicolumn{5}{|c|}{ Baseline WHO clinical stages } \\
\hline Stage I & 1 & - & 1 & - \\
\hline Stage II & $1.805(1.157,2.815)$ & $0.009^{*}$ & $1.279(0.810,2.019)$ & 0.291 \\
\hline Stage III & $2.172(1.446,3.264)$ & $0.000^{*}$ & $1.003(0.651,1.544)$ & 0.990 \\
\hline Stage IV & $3.541(2.294,5.467)$ & $0.000^{*}$ & $1.604(1.017,2.531)$ & $0.042^{*}$ \\
\hline \multicolumn{5}{|l|}{ Function status } \\
\hline Working status & 1 & - & 1 & - \\
\hline Ambulatory status & $1.724(1.302,2.282)$ & $0.000^{*}$ & $1.248(0.930,1.676)$ & 0.140 \\
\hline Bedridden status & $4.855(3.618,6.516)$ & $0.000^{*}$ & $2.543(1.860,3.476)$ & $0.000^{*}$ \\
\hline \multicolumn{5}{|l|}{ Marital status } \\
\hline Married & 1 & - & 1 & - \\
\hline Single & $3.380(2.498,4.574)$ & $0.000^{*}$ & $2.704(1.979,3.693)$ & $0.000^{*}$ \\
\hline Separated & $2.087(1.413,3.082)$ & $0.000^{*}$ & $1.737(1.157,2.608)$ & $0.008^{*}$ \\
\hline Divorced & $2.281(1.517,3.430)$ & $0.000^{*}$ & $2.105(1.391,3.188)$ & $0.000^{*}$ \\
\hline Widowed & $3.041(1.941,4.763)$ & $0.000^{*}$ & $2.379(1.498,3.778)$ & $0.000^{*}$ \\
\hline
\end{tabular}

*Variables significantly associated with patient mortality (outcome) at $95 \%$ level significance $(p<0.05)$.

those with younger age patients enrolled on ART $[9,11,13,26]$. This could be due to the fact that individuals are at higher risk of complications and respond poorly to ART, as a result of combined effect of aging, HIV infection, and antiretroviral treatment. In addition, it is known that as age increases, im- mune status becomes incompetent, which is considered to be a risk for many chronic diseases, leading to death.

There was also a significant positive association between substance users with mortality in the current study. Patients who were using substances, such as alcohol, tobacco, and 
kchat, or other drugs at baseline, showed almost a 2-fold higher risk of mortality compared to those who did not use substances (AHR $=1.79$; 95\% CI: 1.40-2.29). In line, a previous study from Wolisso and Gonder in Ethiopia, revealed that patients who were using substances, like alcohol, tobacco, and kchat usage, or other drugs at baseline, presented a 2 -fold higher risk of mortality compared to patients who did not use substances $[10,11,17,27]$. This might be that alcohol, tobacco, and kchat, or other drugs utilization can affect patients' immune system, and may speed up the progression of the disease.

Likewise, patients with lower educational levels (no formal education or primary education) at baseline were found to be almost 2-times more likely to die than those with higher educational levels: AHR $=2.07 ; 95 \%$ CI: $1.10-3.90$ and $\mathrm{AHR}=1.90$; 95\% CI: 1.01-3.57, respectively. In line with this, a previous study done in Aksum and Gonder, northern Ethiopia by Tadesse et al. and Zinabu et al., revealed that patients with lower educational levels (no or primary education) at baseline were found to be 2.6-times more likely to die than those with higher educational levels $[11,28,29]$. This might be happened due to lack of psychological, mental, healthcare, and economic awareness of less educated patients. In addition, patients with higher level of education might have a better understanding about the importance of compliance to their drugs, and afford good quality of foods in a better way than those with low level of education.

This research also revealed that the patients with WHO clinical stage IV had a $40 \%$ higher risk of mortality than patients with WHO clinical stage I, controlling for other variables in the model (AHR $=1.60 ; 95 \%$ CI: 1.02-2.53). This finding is in accordance with results of majority of previous studies conducted in northern and eastern Ethiopia, which revealed that patients with WHO clinical stage IV had a 2 -fold or higher risk of dying compared to patients with WHO clinical stage I $[10,12,20-23,30]$. This might be that patients in advanced clinical stages are prone for TB infection. Additionally, this could be associated with immune reconstitution syndrome and worsening of drug toxicity in these particular patients. Therefore, it is unquestionable whether ART should be initiated as early as possible, prior to advanced clinical stages.

Functional status during ART initiation was also another significant predictor of mortality in the current study. The risk of mortality was 2.5-times higher for those who presented bedridden status compared to those with working functional status (AHR $=2.54$; 95\% CI: 1.86-3.48). This finding is consistent with many investigations done in the past in Ethiopia. A study done in eastern Ethiopia demonstrated that risk of mortality was almost 6-times higher for patients with bedridden functional status than working ones $[12,19]$. Another study conducted in Debremarkos in northern Ethiopia indicated that baseline ambulatory and bedridden functional status had 2.7- and 2.4-times higher risk of death than working patients, respectively $[14,30]$. Several other studies have also found an association between functional status and mortality of HIV/AIDS-infected patients [10, 15, 17, 20, 22, 30]. Therefore, patients who present with ambulatory and bedridden functional status should obtain particular attention in order to reduce their mortality rate.

Marital status was a strong predictor of mortality in the current study. Patients' with single-marital status had nearly 3-times higher risk of dying as compared to married patients $(\mathrm{AHR}=2.70$; 95\% CI: 1.98-3.69). Moreover, divorced and windowed patients' had a 2-fold higher risk of dying compared to married patients: AHR $=2.10 ; 95 \%$ CI: $1.39-3.19 \%$ and AHR $=2.38$; 95\% CI: $1.50-3.78$, respectively. Likewise, patients' presented with separated marital status had a $30 \%$ higher risk of mortality compared to married patients $(\mathrm{AHR}=1.74 ; 95 \% \mathrm{CI}: 1.16-2.61)$. This result was similar to the findings of previous research $[12,19]$. This difference might be explained by married patients' psychological preparedness to seek partners' and social support, and understand the importance of adherence to ART.

\section{Conclusions}

In the present study, the mortality rate was very high in the earlier months of HAART initiation and tended to later stabilize. During the follow-up period, 273 (21\%) of patients deceased, of whom around $32 \%$ and $12 \%$ of deaths occurred within 6 months and between 6 and 12 months of HAART initiation, respectively. The majority of patients were not using condom during sexual intercourse (59\%) and $40 \%$ of the patients were substances (alcohol, tobacco, kchat etc.) users.

Kaplan-Meir survival figures showed that patients with no concomitant TB infection, those not using substances, with CD4 count greater than $350 \mathrm{cell} / \mathrm{mm}^{3}$, working, urban dwellers, with WHO clinical stage I, and those who had no past history of opportunistic illnesses, had better survival experience as compared to their counterparts. The multivariable Cox proportional hazards model demonstrated that having concomitant $\mathrm{TB}$ infection, low baseline CD4 count, low baseline weight, being rural area dweller, being substance user, older age, lower educational levels, higher WHO clinical stages, functional status, and marital status, were all significantly associated with progression to death for HIV/AIDS-infected patients.

\section{Ethical consideration}

Ethical clearance was obtained from institutional research ethics review committee of Tepi campus, Mizan-Tepi University. As the study was conducted through review of medical records, every patient would not be subject to any harm, as long as confidentiality is maintained. In addition, no name or personal identifications were used on data collection form. The recorded data were not accessed by a third person, except the principal investigators, and confidentially of data was maintained.

\section{Acknowledgements}

The authors would like to express their heartfelt gratitude and appreciation to Mizan-Tepi University and Department of Statistics, for granting financial and logistic 
support to this study. Our earnest thanks also go to data collectors and supervisors, who spent their valuable time recording the data from patients forms. We are also grateful to the manager of Mizan-Tepi University Teaching Hospital office for facilitating conditions while conducting this study.

\section{Conflict of interest}

The authors have no conflict of interest.

\section{References}

1. Federal HIV/AIDS Prevention and Control Office (HAPCO). Country Progress Report on HIV/AIDS Response, Federal Republic of Ethiopia; 2017.

2. Badri M, Wilson D, Wood R. Effect of highly active antiretroviral therapy on incidence of tuberculosis in South Africa: a cohort study. Lancet 2002; 359: 2059-2064.

3. UNAIDS. Factsheet-World AIDS day 1 december 2020: Global HIV Statistics. Geneva; 2020.

4. World Health Organization. Global Update on the Health Sector Response to HIV, Geneva; 2020.

5. Federal HIV/AIDS Prevention and Control Office (FHPCO). Guidance for implementation of Antiretroviral Therapy Program in Ethiopia; 2018.

6. Federal Ministry of Health. Antiretroviral Therapy in Ethiopia. Addis Ababa, Ethiopia; 2018.

7. Lawn SD, Harries AD, Anglaret X, Myer L, Wood R. Early mortality among adults accessing ART programmers in sub-Saharan Africa. AIDS 2008; 22: 1897-1908.

8. Tsehaineh B. Assessment of factors associated with high risk of mortality of HIV patients treated with highly active antiretroviral therapy in Zimma zone, south western Ethiopia: application of survival analysis methods. MSc thesis. Addis Ababa University; 2010 (Unpublished result).

9. Kebede A, Tessema F, Bekele G, Kura Z, Merga H. Epidemiology of survival pattern and its predictors among HIV positive patients on highly active antiretroviral therapy in Southern Ethiopia public health facilities: a retrospective cohort study. AIDS Res Ther 2020; 17: 49.

10. Tachbele E, Ameni G. Survival and predictors of mortality among human immunodeficiency virus patients on anti-retroviral treatment at Jinka Hospital, South Omo, Ethiopia: a six years retrospective cohort study. Epidemiol Health 2016; 38: e2016049.

11. Teka Z, Mohammed K, Workneh G, Gizaw Z. Survival of HIV/ AIDS patients treated under ART follow-up at the University hospital, northwest Ethiopia. Environ Health Prev Med 2021; 26: 52.

12. Damtew B, Mengistie B, Alemayehu T. Survival and determinants of mortality in adult HIV/AIDS patients initiating antiretroviral therapy in Somali Region, Eastern Ethiopia. Pan Afr Med J 2015; 22: 138.

13. Jemal A, Helen M, Omprakash S, Anteneh W. Identifying factors related to the survival of AIDS patients under the follow-up of antiretroviral therapy (ART): the case of South Wollo. Int J Data Envelop Anal Oper Res 2014; 1: 21-27.

14. Birhanu H, Alle A, Birhanu MY. Rate and Predictors of Mortality Among Adults on Antiretroviral Therapy at Debre Markos Referral Hospital, North West Ethiopia. HIV AIDS (Auckl) 2021; 13: 251-259.

15. Biset Ayalew M. Mortality and its predictors among HIV infected patients taking antiretroviral treatment in Ethiopia: a systematic review. AIDS Res Treat 2017; 2017: 5415298.

16. Poka-Mayap V, Pefura-Yone EW, Kengne AP, Kuaban C. Mortality and its determinants among patients infected with HIV-1 on antiretroviral therapy in a referral centre in Yaounde, Cameroon: a retrospective cohort study. BMJ Open 2013; 3: e003210. doi:10.1136/ bmjopen-2013-003210.
17. Arigawu AS, Gemechu B. Determining factors that affect the survival status of HIV infected patients under ART: The case of St. Luke Catholic Hospital and College of Nursing (SLCHCN), Woliso, Ethiopia. Int J of Basic and App Sci 2015; 1: 19-36.

18. Chakravarty J, Tiwary NK, Prasad SR, et al. Determinants of survival in adult HIV patients on antiretroviral therapy in Eastern Uttar Pradesh: a prospective study. Indian J Med Res 2014; 140: 491-500.

19. Nigussie F, Alamer A, Mengistu Z, Tachbele E. Survival and Predictors of Mortality Among Adult HIV/AIDS Patients Initiating Highly Active Antiretroviral Therapy in Debre-Berhan Referral Hospital, Amhara, Ethiopia: A Retrospective Study. HIV AIDS (Auckl) 2020; 12: 757-768.

20. Ayele W, Mulugeta A, Desta A, Rabito FA. Treatment outcomes and their determinants in HIV patients on Anti-retroviral treatment program in selected health facilities of Kembata and Hadiya zones, Southern Nations, Nationalities and Peoples Region, Ethiopia. BMC Public Health 2015; 15: 826.

21. Tadele A, Shumey A, Hiruy N. Survival and predictors of mortality among adult patients on highly active antiretroviral therapy at Debremarkos referral hospital, North West Ethiopia; a retrospective cohort study. J AIDS Clin Res 2014: 5: 280.

22. Chernet AG, Biru MD. Survival analysis of HIV/AIDS patients under ART follow up in Attat referral hospital. Sc J of App Math and Stat 2020; 8: 42-46.

23. Eticha EM, Gemeda AB. Predictors of mortality among adult patients enrolled on Antiretroviral Therapy in Hiwotfana specialized University Hospital, Eastern Ethiopia: Retrospective Cohort study. J HIV Clin Sci Res 2018; 5: 007-011. DOI: http://doi. org/10.17352/2455-3786.000127.

24. Kusumaadhi ZM, Farhanah N, Udji Sofro MA. Risk factors for mortality among HIV/AIDS patients. Diponegoro Int Med J [Online] 2021; 2: 20-29. DOI: https://doi.org/10.14710/dimj.v2i1.9667.

25. Cornell M, Myer L, Kaplan R, Bekker LG, Wood R. The impact of gender and income on survival and retention in a South African antiretroviral therapy programme. Trop Med Int Health 2009; 14: 722-731.

26. Seyoum D, Degryse JM, Kifle YG, et al. Risk Factors for Mortality among Adult HIV/AIDS Patients Following Antiretroviral Therapy in Southwestern Ethiopia: An Assessment through Survival Models. Int J Environ Res Public Health 2017; 14: 296.

27. Misgina KH, Weldu MG, Gebremariam TH, et al. Predictors of mortality among adult people living with HIV/AIDS on antiretroviral therapy at Suhul Hospital, Tigrai, Northern Ethiopia: a retrospective follow-up study. J Health Popul Nutr 2019; 38: 37.

28. Tsegaye AT, Alemu W, Ayele TA. Incidence and determinants of mortality among adult HIV infected patients on second-line antiretroviral treatment in Amhara region, Ethiopia: a retrospective follow up study. Pan Afr Med J 2019; 33: 89.

29. Tadesse K, Haile F, Hiruy N. Predictors of mortality among patients enrolled on antiretroviral therapy in Aksum Hospital, Northern Ethiopia: a retrospective cohort study. PLoS One 2014; 9: e87392. DOI: 10.1371/journal.pone.0087392.

30. Abebe N, Alemu K, Asfaw T, Abajobir AA. Predictors of mortality among HIV positive adults on antiretroviral therapy in Debremarkos referral Hospital, Northwest Ethiopia. J AIDS HIV Res 2014; 6: 19-27. 